\title{
ENDOCRINOLOGY IN THE TIME OF COVID-19-2021 UPDATES The management of diabetes insipidus and hyponatraemia
}

\section{Mirjam Christ-Crain', Ewout J Hoorn², Mark Sherlock ${ }^{3}$, Chris J Thompson ${ }^{3}$ and John Wass ${ }^{4}$}

'Division of Endocrinology, Diabetes and Metabolism, Department of Clinical Research, University Hospital Basel, University of Basel, Basel, Switzerland, ${ }^{2}$ Division of Nephrology and Transplantation, Department of Internal Medicine, Erasmus MC, University Medical Center Rotterdam, Rotterdam, The Netherlands, ${ }^{3}$ Academic Department of Endocrinology, Beaumont Hospital/RCSI Medical School, Dublin, Ireland, and ${ }^{4}$ Department of Endocrinology, Oxford Centre for Diabetes, Endocrinology and Metabolism, Churchill Hospital, Oxford, UK

This manuscript is part of a commissioned series of urgent clinical guidance documents on the management of endocrine conditions in the time of COVID-19. This clinical guidance document underwent expedited open peer review by Joe Verbalis (USA), Jens Otto Jørgensen (Denmark), Stefan Bilz (Switzerland) and Georg Lindner (Switzerland).

Correspondence should be addressed to $M$ Christ-Crain Email mirjam.christ-crain@usb.ch

\begin{abstract}
COVID-19 has changed the nature of medical consultations, emphasizing virtual patient counselling, with relevance for patients with diabetes insipidus (DI) or hyponatraemia. The main complication of desmopressin treatment in DI is dilutional hyponatraemia. Since plasma sodium monitoring is not always possible in times of COVID-19, we recommend to delay the desmopressin dose once a week until aquaresis occurs allowing excess retained water to be excreted. Patients should measure their body weight daily. Patients with DI admitted to the hospital with COVID-19 have a high risk for mortality due to volume depletion. Specialists must supervise fluid replacement and dosing of desmopressin. Patients after pituitary surgery should drink to thirst and measure their body weight daily to early recognize the development of postoperative SIAD. They should know hyponatraemia symptoms. Hyponatraemia in COVID-19 is common with a prevalence of 20-30\% and is mostly due to SIAD or hypovolaemia. It mirrors disease severity and is an early predictor of mortality. Hypernatraemia may also develop in COVID-19 patients, with a prevalence of 3-5\%, especially in ICU, and derives from different multifactorial reasons, for example, due to insensible water losses from pyrexia, increased respiration rate and use of diuretics. Hypernatraemic dehydration may contribute to the high risk of acute kidney injury in COVID-19. IV fluid replacement should be administered with caution in severe cases of COVID-19 because of the risk of pulmonary oedema.
\end{abstract}

\section{Introduction}

This is an update of the previously published guidelines 1 year ago (1). While there is not much new literature about diabetes insipidus (DI) and COVID-19, knowledge about the prevalence of dysnatraemia in COVID-19 and about the association of dysnatraemia with the outcome has increased.

Patients with pre-existing endocrine conditions may be vulnerable to perturbations in plasma sodium in more severe cases of COVID-19. Especially patients with central DI or pre-existing hyponatraemia may be at risk of more severe, life-threatening dysnatraemia. Regardless of pre-existing endocrine conditions, hyponatraemia is common in patients hospitalized with COVID-19 (2, $3,4,5,6,7,8,9)$ and is associated with disease severity and mortality. Printed in Great Britain

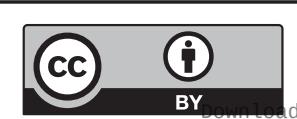

This work is licensed under a Creative Commons Attribution 4.0 International License.

from Bioscientifica,com at $04 / 26 / 2023$ 01:06:42PM 
This article is intended to advise how endocrinologists can still optimally care for ambulatory patients with central DI and hyponatraemia, where regular physical consultations and biochemical assessments are not possible. Furthermore, we provide guidance on the management of these patients when they are admitted to the hospital with severe COVID-19.

\section{Diabetes insipidus}

DI is a rare disease (10), characterized by hypotonic polyuria and polydipsia (11). The differential diagnosis of DI involves the distinction between primary forms (central DI) or nephrogenic DI and secondary forms, where polyuria results from primary polydipsia (12). Treatment of DI consists of fluid administration in case of dehydration, and in cases of central DI, desmopressin as hormone replacement for the absent vasopressin (13).

\section{How to manage patients with an established diagnosis of diabetes insipidus in the time of COVID-19}

\section{Management of patients with central DI in the outpatient setting}

- In the majority of cases with central DI, osmoregulated thirst is intact, and oral fluid intake accurately compensates for urinary and insensible water losses. Even prior to treatment with desmopressin, patients are, therefore, typically eunatraemic. To reduce the symptoms of polyuria and polydipsia, desmopressin is given orally or intranasally; the major complication of desmopressin therapy is hyponatraemia. A retrospective review has shown that $27 \%$ of central DI patients show mild hyponatraemia (131-134 mmol/L) on routine electrolyte testing, and 15\% develop more severe hyponatraemia ( $\leq 130 \mathrm{mmol} / \mathrm{L})$ over longterm follow-up (14). Hyponatraemia develops when the antidiuretic effects of continuous desmopressin therapy prevent free water excretion, even with normal fluid intakes. This can be prevented by delaying doses of desmopressin to allow regular aquaresis, but regular electrolyte checks are recommended during the initiation of therapy. Annual electrolyte checking is recommended for long-term follow-up, though more frequent monitoring is needed where hyponatraemia episodes are more frequent.

- $\quad$ The COVID-19 pandemic has limited the accessibility of blood testing, and the priority of routine treatment of central DI should be to avoid hyponatraemia. This emphasizes the importance of delaying desmopressin doses, to allow regular periods of free water clearance, so that excess water intake does not lead to dilutional hyponatraemia. This can be achieved by recommending that the patient delays a dose of desmopressin once or twice per week, until an aquaresis occurs. Some patients regularly delay each dose until they begin to feel polyuric, as they are aware that they otherwise feel bloated by fluid retention. Alternatively, especially in patients known to experience recurrent hyponatraemia, one dose each week can be entirely omitted, though significant polyuria and social disruption may occur.

\section{Acute infection with suspected or confirmed COVID-19}

- Although patients with central DI should be no more vulnerable to COVID-19 than the rest of the population, those DI patients who develop respiratory complications of COVID-19 are at significantly increased risk of dysnatraemia.

Epidemiological data show that hypernatraemia is rare in ambulatory patients with DI; in contrast, the rate of hypernatraemia during hospital admission is significant (14). The aetiology of this hypernatraemia is multifactorial; if cognition is attenuated by critical illness, fluid intake may be reduced, and if the patient is vomiting, oral desmopressin intake may be difficult. Most hospital studies report increased mortality in intensive care units associated with hypernatraemia (15), and it is a poor prognostic sign in patients who develop DI following head injury (16). In addition, data from a nationwide Swiss cohort study showed an increased mortality rate in complex hypopituitary patients with central DI admitted to hospital, compared with hypopituitary patients without DI, consistent with vulnerability of DI patients to develop hypernatraemic dehydration in the context of severe illness (17). The propensity to develop hypernatraemia during hospital admission is particularly marked in patients with adipsic DI (14), and this subgroup of DI patients has been documented to develop severe hypernatraemia (18), which may be complicated by thrombotic episodes (19). Patients with adipsic DI may also have hypothalamic obesity, and there is increasing evidence that obesity per se may be an important risk factor for poor outcome in patients with Covid19. Thus, these patients may be amongst the most 
vulnerable and should have a very close follow-up in case of any superimposed illness.

- In addition, since patients with nephrogenic DI do not respond to desmopressin, they are particularly prone to severe hypernatraemia with inadequate fluid replacement.

- In 2018, the Society for Endocrinology (SfE) published guidelines on in-hospital management of central DI (20). This report was prompted by a study of patients hospitalized with central DI, which showed that desmopressin treatment had been missed or delayed in $88 \%$ of admissions, and that $35 \%$ of patients consequently developed dysnatraemia (21). This was attributed to a lack of understanding of the critical nature of desmopressin amongst clinical staff (22). In this context, it is very important that patients themselves are empowered with the knowledge of their condition and the essential difference between DI and diabetes mellitus, which caused confusion with serious consequences at the time of admission. The results of these guidelines have generated a sensible basis for the management of DI when patients are admitted to the hospital.

- The key practice points in the SfE in 2018 guidelines are particularly valid for DI patients with COVID19. Most importantly, all patients with central DI admitted to the hospital with COVID-19 should be managed in consultation with endocrinology advice. In addition, a careful prescribing alert system for all patients treated with desmopressin is recommended to reduce prescribing errors and to ensure that essential desmopressin therapy is maintained.

- In patients with mild COVID-19 cold symptoms, who are alert and able to drink, it may, in some patients, be advisable to prescribe oral rather than nasal desmopressin due to the limited absorption from congested nasal passages. As COVID-19 is characterized by persistent fever and tachypnoea, insensible water losses are likely to be substantially increased; ordinarily, osmotically stimulated drinking should generate fluid intake sufficient to make up for insensible losses, but if the cognitive function is impaired by fever, hypoxia or sepsis, i.v. fluids may be required.

- In patients with severe COVID illness, desmopressin should be given parenterally, usually with a starting dose of $0.5 \mu \mathrm{g}$.

The i.v. route is generally preferred because it obviates concerns about absorption and has the same total duration of action as the other parenteral routes. Prompt reduction in urine output should occur, and the antidiuretic effect generally lasts for $6-12 \mathrm{~h}$. Urine osmolality and urine volume should be monitored to ascertain whether the dose was effective, and the plasma sodium should be measured at frequent intervals (every 2-4 h) to ensure improvement of hypernatraemia. Since arterial blood gas point of care testing for sodium may be the main laboratory estimation available in some hospitals (particularly 'field hospitals'), sodium measurement can be done using this method instead of sending it to the laboratory.

Hypernatraemia in COVID-19 patients (without central DI) in intensive care units is seen with a prevalence of $2-5 \%(2,4,5,6,7,8)$; excessive insensible water losses from the constant pyrexia and increased respiration rate may play a major aetiological role in this, as well as this gives rise to the need for significant diuretic use or conservative fluid regimens in some patients in order to aid oxygenation. Hypernatraemic dehydration may, therefore, rapidly develop in patients with DI, particularly in those who need diuretic therapy or in whom desmopressin is withheld or delayed. If diuresis is necessary, the optimum management of these patients should be a collaboration between intensive care and endocrinology.

- In patients with hypovolaemic shock due to COVID-19 restoration of blood volume with i.v. $0.9 \%$ sodium chloride is preferable, even if there is hypernatraemia. In the absence of hypovolaemic shock, patients with DI and severe dehydration should be treated with hypotonic fluids, either enterally (using water or milk) or, if necessary, intravenously (using $5 \%$ dextrose in water). Hypotonic fluids should be administered as an i.v. infusion, with the rate adjusted to exceed the hourly urine output and reverse the calculated total body water deficit. The usual aim is to provide just enough water to safely normalize serum sodium at a rate of $<0.5 \mathrm{mmol} / \mathrm{L}$ per $\mathrm{h}(<10-12 \mathrm{mmol} / \mathrm{L}$ per day) (23). However, the issue is complicated in COVID-19 by other priorities of management in severe disease. Advanced cardiorespiratory complications of COVID-19 are characterized mainly by acute respiratory distress syndrome (ARDS), with significant pulmonary oedema, and sometimes by acute kidney injury (24). Patients who are seriously ill need diuretic therapy to support the lungs or renal replacement therapy if there is concurrent acute kidney injury with reduced urine output. Intensive care colleagues may be reluctant to reverse hypernatraemia with i.v. hypotonic fluids, because of the risk of pulmonary oedema. Of note, however, hypotonic fluids are less likely to cause 
extracellular volume expansion since two-thirds of the administered fluid is distributed intracellularly.

Initial data suggested that hypernatraemia, in contrast to other critically ill patients, is not a risk factor for severe mortality in COVID-19 (25). More recent data, however, show that hypernatraemia is associated with adverse outcomes and mortality, similar to other critically ill patients $(4,5,6,7)$.

- However, it may be that endocrinologists may have to accept mild hypernatraemia $(<155 \mathrm{mmol} / \mathrm{L})$ as the price of preventing pulmonary oedema. In patients with central DI. we will have a major role in ensuring that severe hypernatraemia, which compromises recovery, does not occur, and multidisciplinary input is needed to discuss the individual merits and contingencies of treatment in DI patients with COVID-19.

- It is important to stress that, as hypernatraemic dehydration is associated with a hypercoagulable state, the risk of venous thrombosis, and pulmonary embolism, is substantial, particularly in an immobile patient (26). We, therefore, recommend the routine prescription of prophylactic s.c. low molecular weight heparin during episodes of hypernatraemic dehydration, until eunatraemia is restored. This is particularly important since pulmonary embolism is emerging as one of the factors associated with mortality in COVID-19 patients. Low molecular weight heparin is also recommended in patients with hypercoagulable states in COVID-19 (27).

- As the majority of patients with postoperative or post-traumatic central DI also have ACTH deficiency, concomitant stress dose corticosteroids are essential during COVID infection.

\section{Hyponatraemia}

Hyponatraemia (plasma sodium $<35 \mathrm{mmol} / \mathrm{L}$ ) is the most common electrolyte disorder in clinical practice (28). It is dividedintoeuvolaemic, hypovolaemic, and hypervolaemic hyponatraemia, each of which is treated differently (29, 30 ). The syndrome of inappropriate antidiuresis (SIAD) is the commonest cause of hyponatraemia $(28,31)$.

\section{How to manage patients with hyponatraemia in the time of COVID-19}

Management of patients with hyponatraemia in the routine endocrine practice

- SIAD is seen by endocrinologists after pituitary or other neurosurgery (32) and as part of consultations throughout the hospital. One effect of the COVID19 pandemic has been the cancellation of most elective pituitary operations, though neurosurgical interventions for subarachnoid haemorrhage or traumatic brain injury continue to induce SIAD. Patients with SIAD will continue to be treated according to well-established guidelines $(29,30)$. As patients who develop SIAD after pituitary surgery characteristically do so after discharge from the hospital, it will continue to be important to draw attention to the possible occurrence of hyponatraemia, to both patients and primary care physicians. Hyponatraemia has been recorded to be the commonest cause of hospital readmission following transsphenoidal surgery; as access to routine phlebotomy may be compromised by the needs for social isolation and the limitations of many health provisions, the emphasis should be on prevention and awareness. Patients should be advised to limit their fluid intake in the 2 weeks following surgery and to drink only to thirst and to measure their body weight daily. We recommend that the primary care physician is contacted if there is weight gain, bloating or unusual headache. Instruction on hyponatraemia-associated symptoms, such as headache, dizziness, nausea or fatigue, is important.

- All other patients with chronic SIAD, who are treated with either fluid restriction, urea or vaptans should be instructed to continue their treatment as usual. We recommend advising the patients to daily monitor their body weight and to be aware of hyponatraemia symptoms (see above), where access to phlebotomy for electrolytes is restricted.

What to look at if patients with hyponatraemia are admitted to the hospital with acute infection with COVID-19

- Hyponatraemia occurs in up to $30 \%$ of pneumonia cases (33), and several studies show that admission hyponatraemia predicts increased mortality and morbidity $(34,35,36)$, independent of the underlying disease. Of note, $60 \%$ of SARS-COV- 1 patients were reported to have mild hyponatraemia (37).

Recent literature suggests that hyponatraemia in COVID-19 patients is as common as in other pneumonia cases. Berni et al. showed a prevalence of hyponatraemia of $22.9 \%$, which is in the range of most other literature showing a prevalence of around $20-30 \%(5,6,7,9)$. An even higher prevalence of $40 \%$ has been shown in a large study in 10000 patients across 13 hospitals in a New York health system (4). Of note, hyponatraemia 
seems to be more common in COVID-19 compared to controls hospitalized with similar symptoms, but without COVID-19 (6). There is only limited information about the aetiology of hyponatraemia, but SIAD and hypovolaemia are suggested to be the main causes. One study identified a correlation between serum sodium and interleukin- 6 and greater correction of hyponatraemia in patients with COVID-19 who were treated with tocilizumab (38). This suggests that interleukin-6-mediated vasopressin release may contribute to COVID-19-associated hyponatraemia $(39,40)$. COVID-19 can also cause adrenal insufficiency with accompanying hyponatraemia responsive to steroid replacement $(41,42)$. In almost all studies, hyponatraemia was associated with an increased prevalence of non-invasive ventilation and ICU transfer and was an independent predictor for adverse outcome and mortality. Each $\mathrm{mmol} / \mathrm{L}$ of serum sodium reduction was associated with a $14.7 \%$ increased risk of death in one study (2). In another study, each level of worsening hyponatraemia (mild to moderate to severe) conferred a $43 \%$ increased odds of in-hospital death, even after adjusting for age, gender, race, BMI, past medical history, laboratory abnormalities, kidney failure, mechanical ventilation and sequential organ failure assessment (SOFA) score. Still, it is unclear whether this association of hyponatraemia and outcome mirrors causality or simply defines hyponatraemia as a marker for severity of the disease. Whatever the case, sodium levels at admission should be considered an early prognostic marker in patients with COVID-19.

As the mortality from hypovolaemic hyponatraemia is higher than that of SIAD (31), the temptation is, if it occurs in COVID-19 patients, to respond with i.v. fluid resuscitation. However, in severely ill COVID-19 patients, clinical experience dictates that caution should be exercised in the rate of i.v. fluid administration because of the risk of precipitating pulmonary oedema. Similar caution is advised in patients with severe hyponatraemia complicated by symptoms of cerebral irritation. Although guidelines recommend bolus hypertonic saline treatment to rapidly elevate plasma sodium concentration (29), and published data suggests that this is effective (43), the sudden volume load might cause pulmonary oedema. In this circumstance, the safer option might be low-dose hypertonic saline infusion, with careful control of the volume of fluid administered; the clinical experience in the COVID-19 situation is insufficient to be definitive about this, and each centre should use the method with which they are most familiar.

Table 1 highlights the risks and preventive measures in patients with DI or hyponatraemia in times of COVID19 and Table 2 shows the management of DI and hyponatraemia in the COVID-19 patient in intensive care.

In summary, patients with central DI or hyponatraemia should be managed according to existing guidelines as ambulatory patients, with careful explanation to DI patients of how to avoid dilutional hyponatraemia in circumstances where plasma sodium measurements are difficult to access. Patients with DI are vulnerable to adverse effects and potentially poor outcomes if hospitalized with COVID-19. Hyponatraemia seems to be common in patients hospitalized with COVID-19 with a prevalence rate

Table 1 Risks and protective measures in DI and hyponatraemia in times of COVID-19.

\begin{tabular}{|c|c|c|}
\hline & Risks & Protective measure \\
\hline \multirow[t]{4}{*}{ Diabetes insipidus } & $\begin{array}{l}\text { Dilutational hyponatraemia as side effect of } \\
\text { desmopressin therapy }\end{array}$ & $\begin{array}{l}\text { Delay desmopressin dose once or twice weekly; } \\
\text { Advise to regularly control body weight } \\
\text { Drink to thirst }\end{array}$ \\
\hline & $\begin{array}{l}\text { High risk for dysnatraemia if admitted to the hospital due } \\
\text { to missed desmopressin dose, reduced fluid intake, } \\
\text { increased insensible losses and the potential need for } \\
\text { diuretic therapy }\end{array}$ & $\begin{array}{l}\text { Endocrine consultation for every patient with DI to } \\
\text { reduce prescribing errors and to advise with } \\
\text { fluid management }\end{array}$ \\
\hline & & Patient empowerment \\
\hline & & $\begin{array}{l}\text { Appropriate stress dosing of corticosteroids in } \\
\text { patients with additional ACTH deficiency }\end{array}$ \\
\hline \multirow[t]{4}{*}{ Hyponatraemia } & $\begin{array}{l}\text { New diagnosis of SIAD after neurosurgical interventions, } \\
\text { brain injury or subarachnoid haemorrhage }\end{array}$ & $\begin{array}{l}\text { Advise to limit fluid intake for } 2 \text { weeks following } \\
\text { surgery/injury }\end{array}$ \\
\hline & & $\begin{array}{l}\text { Measure body weight daily and aim to stay at } \\
\text { eunatraemic weight }\end{array}$ \\
\hline & & Drink only to thirst \\
\hline & & Know the early symptoms of hyponatraemia \\
\hline
\end{tabular}


Table 2 Management of DI and hyponatraemia in the COVID-19 patient in intensive care setting

$\overline{\text { Diabetes insipidus }} \frac{\text { Clinical scenario }}{\text { Routine care }}$

Hypernatraemic dehydration

Hyponatraemia Routine care

Hypovolaemic hyponatraemia

Acute severe hyponatraemia with CNS irritation

Exclude adrenal insufficiency

\section{Action}

As per published guidelines

Careful attention to desmopressin dose and fluids

Hypotonic IV fluids

Urine losses + insensible losses $=$ agreed target to reverse hypernatraemia

Careful monitoring for ARDS and pulmonary oedema

Prophylactic anticoagulation

As per published guidelines

IV $0.9 \%$ sodium chloride solution

Rate individualized to patient and agreed with intensivists

Careful monitoring for ARDS and pulmonary oedema

Aim to elevate $\mathrm{pNa}$ by $8-12 \mathrm{mmol} / \mathrm{L} / 24 \mathrm{~h}$

Continuous IV infusion of $3 \%$ saline recommended to

control fluid load or careful IV bolus 3\% saline

Monitor pNa every 2-4 h

AKI, acute kidney injury; pNa, plasma sodium concentration.

of around $20-30 \%$, mainly due to SIAD or hypovolaemia. Hypernatraemia is less common (prevalence of 2-5\%) and is more a problem of COVID-19 in intensive care units, most probably due to insensible water losses from the constant pyrexia and due to increased respiration rate. This tendency may be enhanced in patients with DI, who are at risk of hypernatraemic dehydration. Treatment of dehydration must be tempered with the potential to precipitate pulmonary oedema with i.v. fluid; treatment plans should be carefully agreed upon between endocrinologists and intensivists. Hyponatraemia in severely COVID-19-affected patients should be treated by guideline principles but with similar caution with respect to the volume of i.v. fluids in hypovolaemic hyponatraemia or in acute hyponatraemia with cerebral irritation.

\section{Declaration of interest}

The authors declare that there is no conflict of interest that could be perceived as prejudicing the impartiality of this guidance.

\section{Funding}

This work did not receive any specific grant from any funding agency in the public, commercial or not-for-profit sector.

\section{Disclaimer}

Due to the emerging nature of the COVID-19 crisis, this document is not based on extensive systematic review or meta-analysis but on rapid expert consensus. The document should be considered as guidance only; it is not intended to determine an absolute standard of medical care. Healthcare staff needs to consider individual circumstances when devising the management plan for a specific patient.

\section{References}

1 Christ-Crain M, Hoorn EJ, Sherlock M, Thompson CJ \& Wass JAH. Endocrinology in the time of COVID-19: management of diabetes insipidus and hyponatraemia. European Journal of Endocrinology 2020 183 G9-G15. (https://doi.org/10.1530/EJE-20-0338)

2 Berni A, Malandrino D, Corona G, Maggi M, Parenti G, Fibbi B, Poggesi L, Bartoloni A, Lavorini F, Fanelli A et al. Serum sodium alterations in SARS CoV-2 (COVID-19) infection: impact on patient outcome. European Journal of Endocrinology 2021185 137-144. (https:// doi.org/10.1530/EJE-20-1447)

3 De Carvalho H, Letellier T, Karakachoff M, Desvaux G, Caillon H, Papuchon E, Bentoumi-Loaec M, Benaouicha N, Canet E, Chapelet G et al. Hyponatremia is associated with poor outcome in COVID-19. Journal of Nephrology 2021 In press. (https://doi.org/10.1007/s40620021-01036-8)

4 Hirsch JS, Uppal NN, Sharma P, Khanin Y, Shah HH, Malieckal DA, Bellucci A, Sachdeva M, Rondon-Berrios H, Jhaveri KD et al. Prevalence and outcomes of hyponatremia and hypernatremia in patients hospitalized with COVID-19. Nephrology, Dialysis, Transplantation 202136 1135-1138. (https://doi.org/10.1093/ndt/ gfab067)

5 Tzoulis P, Waung JA, Bagkeris E, Hussein Z, Biddanda A, Cousins J, Dewsnip A, Falayi K, McCaughran W, Mullins C et al. Dysnatremia is a predictor for morbidity and mortality in hospitalized patients with COVID-19. Journal of Clinical Endocrinology and Metabolism 2021106 1637-1648. (https://doi.org/10.1210/clinem/dgab107)

6 Atila C, Sailer CO, Bassetti S, Tschudin-Sutter S, Bingisser R, Siegemund M, Osswald S, Rentsch K, Rueegg M, Schaerli S et al. Prevalence and outcome of dysnatremia in patients with COVID-19 compared to controls. European Journal of Endocrinology 2021184 409-418. (https://doi.org/10.1530/EJE-20-1374)

7 Ruiz-Sánchez JG, Núñez-Gil IJ, Cuesta M, Rubio MA, MarounEid C, Arroyo-Espliguero R, Romero R, Becerra-Muñoz VM, Uribarri A, Feltes G et al. Prognostic impact of hyponatremia and hypernatremia in COVID-19 pneumonia: a hope-COVID-19 (health outcome predictive evaluation for COVID-19) registry analysis. Frontiers in Endocrinology 202011 599255. (https://doi.org/10.3389/ fendo.2020.599255)

8 Hu W, Lv X, Li C, Xu Y, Qi Y, Zhang Z, Li M, Cai F, Liu D, Yue J et al. Disorders of sodium balance and its clinical implications in COVID-19 patients: a multicenter retrospective study. Internal and Emergency Medicine 2021 16 853-862. (https://doi.org/10.1007/s11739-020-02515-9) 
9 Frontera JA, Valdes E, Huang J, Lewis A, Lord AS, Zhou T, Kahn DE, Melmed K, Czeisler BM, Yaghi S et al. Prevalence and impact of hyponatremia in patients with coronavirus disease 2019 in New York City. Critical Care Medicine 202048 e1211-e1217. (https://doi. org/10.1097/CCM.0000000000004605)

10 Di Iorgi N, Napoli F, Allegri AE, Olivieri I, Bertelli E, Gallizia A, Rossi A \& Maghnie M. Diabetes insipidus: diagnosis and management. Hormone Research in Paediatrics 201277 69-84. (https://doi. org/10.1159/000336333)

11 Robertson GL. Diabetes insipidus. Endocrinology and Metabolism Clinics of North America 199524 549-572. (https://doi.org/10.1016/S08898529(18)30031-8)

12 Christ-Crain M, Bichet DG, Fenske WK, Goldman MB, Rittig S, Verbalis JG \& Verkman AS. Diabetes insipidus. Nature Reviews: Disease Primers 20195 54. (https://doi.org/10.1038/s41572-019-0103-2)

13 Oiso Y, Robertson GL, Norgaard JP \& Juul KV. Clinical review: Treatment of neurohypophyseal diabetes insipidus. Journal of Clinical Endocrinology and Metabolism 201398 3958-3967. (https://doi. org/10.1210/jc.2013-2326)

14 Behan LA, Sherlock M, Moyles P, Renshaw O, Thompson CJ, Orr C, Holte K, Salehmohamed MR, Glynn N, Tormey W et al. Abnormal plasma sodium concentrations in patients treated with desmopressin for cranial diabetes insipidus: results of a long-term retrospective study. European Journal of Endocrinology 2015172 243-250. (https:// doi.org/10.1530/EJE-14-0719)

15 Darmon M, Timsit JF, Francais A, Nguile-Makao M, Adrie C, Cohen Y, Garrouste-Orgeas M, Goldgran-Toledano D, Dumenil AS, Jamali S et al. Association between hypernatraemia acquired in the ICU and mortality: a cohort study. Nephrology, Dialysis, Transplantation 201025 2510-2515. (https://doi.org/10.1093/ndt/gfq067)

16 Hannon MJ, Crowley RK, Behan LA, O'Sullivan EP, O'Brien MM, Sherlock M, Rawluk D, O’Dwyer R, Tormey W \& Thompson CJ. Acute glucocorticoid deficiency and diabetes insipidus are common after acute traumatic brain injury and predict mortality. Journal of Clinical Endocrinology and Metabolism 201398 3229-3237. (https://doi. org/10.1210/jc.2013-1555)

17 Kutz A, Ebrahimi F, Aghlmandi S, Wagner U, Bromley M, Illigens B, Siepmann T, Schuetz P, Mueller B \& Christ-Crain M. Risk of adverse clinical outcomes in hyponatremic adult patients hospitalized for acute medical conditions: a population-based cohort study. Journal of Clinical Endocrinology and Metabolism 2020105 3428-3436. (https:// doi.org/10.1210/clinem/dgaa547)

18 Crowley RK, Sherlock M, Agha A, Smith D \& Thompson CJ. Clinical insights into adipsic diabetes insipidus: a large case series. Clinical Endocrinology 200766 475-482. (https://doi.org/10.1111/j.13652265.2007.02754.x)

19 Cuesta M, Hannon MJ \& Thompson CJ. Adipsic diabetes insipidus in adult patients. Pituitary 201720 372-380. (https://doi.org/10.1007/ s11102-016-0784-4)

20 Baldeweg SE, Ball S, Brooke A, Gleeson HK, Levy MJ, Prentice M, Wass J $\&$ Society for Endocrinology. Society for Endocrinology Clinical Guidance: inpatient management of cranial diabetes insipidus. Endocrine Connections 20187 G8-G11. (https://doi.org/10.1530/EC-180154)

21 Gleeson H, Bonfield A, Hackett E \& Crasto W. Concerns about the safety of patients with diabetes insipidus admitted to hospital. Clinical Endocrinology 201684 950-951. (https://doi.org/10.1111/cen.13028)

22 Levy M, Prentice M \& Wass J. Diabetes insipidus. BMJ 20193641321. (https://doi.org/10.1136/bmj.1321)

23 Sterns RH. Treatment of severe hyponatremia. Clinical Journal of the American Society of Nephrology 201813 641-649. (https://doi. org/10.2215/CJN.10440917)

24 Zhou F, Yu T, Du R, Fan G, Liu Y, Liu Z, Xiang J, Wang Y, Song B, Gu X et al. Clinical course and risk factors for mortality of adult inpatients with COVID-19 in Wuhan, China: a retrospective cohort study. Lancet
2020395 1054-1062. (https://doi.org/10.1016/S0140-6736(20)305663)

25 Guo T, Fan Y, Chen M, Wu X, Zhang L, He T, Wang H, Wan J, Wang X \& Lu Z. Cardiovascular implications of fatal outcomes of patients with coronavirus disease 2019 (COVID-19). JAMA Cardiology 20205 811-818. (https://doi.org/10.1001/jamacardio.2020.1017)

26 Miljic D, Miljic P, Doknic M, Pekic S, Stojanovic M, Petakov M \& Popovic V. Adipsic diabetes insipidus and venous thromboembolism (VTE): recommendations for addressing its hypercoagulability. Hormones 201413 420-423. (https://doi.org/10.14310/ horm.2002.1496)

$27 \mathrm{Li} \mathrm{T}$, Lu H \& Zhang W. Clinical observation and management of COVID-19 patients. Emerging Microbes and Infections 20209 687-690. (https://doi.org/10.1080/22221751.2020.1741327)

28 Upadhyay A, Jaber BL \& Madias NE. Incidence and prevalence of hyponatremia. American Journal of Medicine 2006119 (Supplement 1) S30-S35. (https://doi.org/10.1016/j.amjmed.2006.05.005)

29 Verbalis JG, Goldsmith SR, Greenberg A, Korzelius C, Schrier RW, Sterns RH \& Thompson CJ. Diagnosis, evaluation, and treatment of hyponatremia: expert panel recommendations. American Journal of Medicine 2013126 (Supplement 1) S1-S42. (https://doi.org/10.1016/j. amjmed.2013.07.006)

30 Spasovski G, Vanholder R, Allolio B, Annane D, Ball S, Bichet D, Decaux G, Fenske W, Hoorn EJ, Ichai C et al. Clinical practice guideline on diagnosis and treatment of hyponatraemia. European Journal of Endocrinology 2014170 G1-G47. (https://doi.org/10.1530/EJE-13-1020)

31 Cuesta M, Garrahy A, Slattery D, Gupta S, Hannon AM, McGurren K, Sherlock M, Tormey W \& Thompson CJ. Mortality rates are lower in SIAD, than in hypervolaemic or hypovolaemic hyponatraemia: results of a prospective observational study. Clinical Endocrinology 201787 400-406. (https://doi.org/10.1111/cen.13388)

32 Hannon MJ, Finucane FM, Sherlock M, Agha A \& Thompson CJ. Clinical review: Disorders of water homeostasis in neurosurgical patients. Journal of Clinical Endocrinology and Metabolism 201297 1423-1433. (https://doi.org/10.1210/jc.2011-3201)

33 Cuesta M, Slattery D, Goulden EL, Gupta S, Tatro E, Sherlock M, Tormey W, O'Neill S \& Thompson CJ. Hyponatraemia in patients with community-acquired pneumonia; prevalence and aetiology, and natural history of SIAD. Clinical Endocrinology 201990 744-752. (https://doi.org/10.1111/cen.13937)

34 Heuman DM, Abou-Assi SG, Habib A, Williams LM, Stravitz RT, Sanyal AJ, Fisher RA \& Mihas AA. Persistent ascites and low serum sodium identify patients with cirrhosis and low MELD scores who are at high risk for early death. Hepatology $2004 \mathbf{4 0} 802-810$. (https://doi. org/10.1002/hep.20405)

35 Kovesdy CP, Lott EH, Lu JL, Malakauskas SM, Ma JZ, Molnar MZ \& Kalantar-Zadeh K. Hyponatremia, hypernatremia, and mortality in patients with chronic kidney disease with and without congestive heart failure. Circulation 2012125 677-684. (https://doi.org/10.1161/ CIRCULATIONAHA.111.065391)

36 Gheorghiade M, Abraham WT, Albert NM, Gattis Stough W, Greenberg BH, O'Connor CM, She L, Yancy CW, Young J, Fonarow GC et al. Relationship between admission serum sodium concentration and clinical outcomes in patients hospitalized for heart failure: an analysis from the OPTIMIZE-HF registry. European Heart Journal 2007 28 980-988. (https://doi.org/10.1093/eurheartj/ehl542)

37 Choi KW, Chau TN, Tsang O, Tso E, Chiu MC, Tong WL, Lee PO, $\mathrm{Ng}$ TK, Ng WF, Lee KC et al. Outcomes and prognostic factors in 267 patients with severe acute respiratory syndrome in Hong Kong. Annals of Internal Medicine 2003139 715-723. (https://doi.org/10.7326/00034819-139-9-200311040-00005)

38 Berni A, Malandrino D, Parenti G, Maggi M, Poggesi L \& Peri A. Hyponatremia, IL-6, and SARS-CoV-2 (COVID-19) infection: may all fit together? Journal of Endocrinological Investigation 202043 1137-1139. (https://doi.org/10.1007/s40618-020-01301-w) 
39 Mastorakos G, Weber JS, Magiakou MA, Gunn H \& Chrousos GP. Hypothalamic-pituitary-adrenal axis activation and stimulation of systemic vasopressin secretion by recombinant interleukin- 6 in humans: potential implications for the syndrome of inappropriate vasopressin secretion. Journal of Clinical Endocrinology and Metabolism 199479 934-939. (https://doi.org/10.1210/jcem.79.4.7962300)

40 Swart RM, Hoorn EJ, Betjes MG \& Zietse R. Hyponatremia and inflammation: the emerging role of interleukin-6 in osmoregulation. Nephron: Physiology 2011118 45-51. (https://doi.org/10.1159/000322238)

41 Hashim M, Athar S \& Gaba WH. New onset adrenal insufficiency in a patient with COVID-19. BMJ Case Reports 202114 e237690. (https:// doi.org/10.1136/bcr-2020-237690)
42 Honore PM, Redant S, Preseau T, Kaefer K, Barreto Gutierrez L, Attou R, Gallerani A \& De Bels D. Understanding the underlying mechanisms of hyponatremia in coronavirus disease 2019 is critical since treatment varies based on etiology: let us not forget critical illness-related corticosteroid insufficiency as the treatment is very different and often lifesaving. Critical Care Medicine 202149 e724-e725. (https://doi. org/10.1097/ccm.0000000000005006)

43 Garrahy A, Dineen R, Hannon AM, Cuesta M, Tormey W, Sherlock M $\&$ Thompson CJ. Continuous versus bolus infusion of hypertonic saline in the treatment of symptomatic hyponatremia caused by SIAD. Journal of Clinical Endocrinology and Metabolism 2019104 3595-3602. (https://doi.org/10.1210/jc.2019-00044)

Received 8 June 2021

Accepted 22 July 2021 